http://dx.doi.org/10.18232/alhe.921

Artículos

\title{
Alternativas de gestión del trabajo en una industria monopólica: el caso de la cementera El Melón, Chile (1930-1950)
}

\section{Work Management Alternatives in a Monopolistic Industry: The Case of the Cement Company El Melón, Chile (1930-1950)}

\author{
Hernán A. Venegas Valdebenito ${ }^{1,}$ * iD 0000-0003-4162-8657
}

Diego A. Morales Barrientos ${ }^{1}$ (D) 0000-0002-8909-2903

${ }^{1}$ Universidad de Santiago de Chile, Santiago, Chile

*Correspondencia: hernan.venegas@usach.cl

Resumen. La principal productora de cemento en Chile, la Sociedad Fábrica de Cemento de El Melón, se emplazó en la pequeña ciudad de La Calera e intervino directamente en el espacio urbano con una serie de iniciativas destinadas a desmovilizar a los trabajadores y afianzar los lazos de lealtad de los mismos hacia la empresa. Apoyada en una situación económica expansiva, El Melón desarrolló prácticas de control extensivo diseñando espacios físicos (poblaciones obreras) y un moderno servicio de bienestar, acercándose a las prácticas del urbanismo paternalista, mediante el cual logró intervenir con éxito en los ámbitos privados de los trabajadores y sus familias, fortaleciendo una identidad obrera ligada a la fábrica.

Palabras clave: industria del cemento; urbanismo paternalista; bienestar social.

CÓMO CITAR: Venegas, H. y Morales, D. (2019). Alternativas de gestión del trabajo en una industria monopólica: el caso de la cementera El Melón, Chile (1930-1950). America Latina en la Historia Económica, 26(1), e921. DOI: 10.18232/alhe.921 
Abstract. The Sociedad Fábrica de Cemento de El Melón, the main company in the production of cement during the first half of the 20th century, it started in the small city of La Calera and directly intervene in the urban space. The company's objective was to strengthen the relationships among workers and managers, as well as the workers' families. With its successful economic expansion, the company designed, built, and maintained two working towns where employees were able to find different ways of social assistance, which were managed by the Welfare Service. These two towns introduced some aspects from the European Natural Hygiene, and it represented in Chile an urban paternalism, which were used to intervene in the working families' domestic space.

Key words: cement company; urban paternalism; social welfare.

JEL: L61, M1, N16, N56, N66.

Recibido: 1 de septiembre de 2017.

Aceptado: 6 de diciembre de 2017.

Publicado: 2 de agosto de 2018

Organismo colaborador: Universidad de Santiago de Chile.

\section{INTRODUCGIÓN}

A comienzos del siglo xx en Chile se propiciaron iniciativas industriales que cubrieran los requerimientos de un rápido crecimiento urbano que se manifestaba no sólo en los volúmenes de población, sino en el crecimiento de las actividades económicas en el centro y sur del país (Kirsch, 1977). Ciudades como Santiago, Valparaíso y Concepción atrajeron gran parte de esa actividad y estimularon con sus demandas nuevos establecimientos industriales en el ámbito metal mecánico, textil, alimentos y bebidas, papel, gas, materiales de construcción y, por cierto, la producción de cemento (Muñoz, 1968; Palma, 1984). Este último, paulatinamente sustituyó poco a poco a otros materiales en la construcción de obras públicas y viviendas al ser un requerimiento indispensable de la más moderna ingeniería (Fernández, 2015) y arquitectura nacional (Mondragón, 2010).

Una parte importante de la demanda de cemento fue cubierta con la importación desde distintos mercados mundiales (Tafunell, 2007, p. 305), pero después de 1908 se contó con la oferta de origen nacional suministrada por la fábrica cementera El Melón, que los propietarios de la sociedad (Kirsch, 1977, p. 197) inauguraron a cerca de cien kilómetros al norte de Santiago, aprovechando los materiales calcáreos de las canteras de La Calera y El Navío como uno de sus principales recursos primarios (Chermakian, 1965). Como otras iniciativas creadas en esa década, El Melón debió sortear la coyuntura crítica que supuso el conflicto mundial iniciado en 1914, las turbulencias sociales de los años veinte y la dramática crisis económica de 1929 (Ortega, 2012). Al mismo tiempo, debió hacer frente a problemas más estructurales derivados de su posición periférica a nivel mundial, dificultades de capitalización, dependencia técnica, así como a la inexistencia de un moderno mercado laboral que contribuyera adecuadamente a la dotación de personal calificado para las tareas de naturaleza industrial que se estaban emprendiendo, problemas que por lo demás debieron enfrentar otras iniciativas del mismo tipo en otras partes mundo (Lemiez, 2007; López, 2010). 
Situados en una coyuntura adversa, los administradores de la cementera ensayaron diversos mecanismos para subsanar uno de sus principales problemas: dotarse de una mano de obra dispuesta a abrazar el trabajo industrial, y atraerla, en una región en que muchos de los trabajadores circulaban, a veces cíclicamente, entre las tareas agrarias, ganaderas y una intensa actividad de pirquinaje minero de características ancestrales ${ }_{1}^{1}$ al menos para esa región del llamado Norte Chico chileno (Videla, 2010). Para ello, edificaron un completo modelo de bienestar social entre sus operarios, esperando asegurar sus condiciones de vida y reproducción. Parte de estos programas surgieron con el siglo debido al convencimiento de que el salario había sido un instrumento insuficiente para persuadir y comprometer al trabajador en la medida en que, como lo sugieren Luc Boltanski y Eve Chiapello, el salario "constituiría, a lo sumo, una razón para permanecer en un empleo, no para implicarse en él” (2002, p. 41). Ante ello, compañías como la cementera El Melón innovaron y al adiestramiento técnico sumaron la idea de protección al trabajo.

La dualidad de ambas estrategias se remonta a un debate ideológico anglosajón más amplio y largo. Casi en la misma época en que el ingeniero estadunidense Frederick Winslow Taylor visualizaba las distintas formas para hacer más eficiente el trabajo industrial a través de la racionalización de los gestos y de las tareas concretas de cada operario en una sucesión encadenada de actividades, base del llamado scientific management (véase en Coriat, 2011, pp. 33-37), el economista británico Alfred Marshall sentaba las bases de una creciente preocupación por los efectos de la actividad productiva en los trabajadores, pues en Principios de economía (1903) observa la "estrecha vinculación entre nivel de vida y eficiencia económica de la población” (véase en Díez, 2014, p. 497). Esta fue la matriz en que convergió el capitalismo reformulado tras la Depresión de 1929 y un punto crítico en los programas de bienestar social tanto a nivel gubernamental como en el caso específico de las industrias, en circunstancia que diseñaron y financiaron sus propios planes de asistencia social. Ciertamente, tales proyectos dependieron de las posibilidades económicas de las empresas de acuerdo a la mayor magnitud y complejidad alcanzada por las grandes corporaciones a fines del siglo xIx (Melling, 1992; Shapayer-Makov, 2004). Pero, junto con ello, también se encuentran diversas raíces ideológicas. El socialismo utópico representado por Robert Owen (Díez, 2014), el higienismo médico-social (Fijalkov, 2012) y el reformismo social de la Iglesia Católica tras la encíclica renun novarum (Valdivieso 2006), formularon desde diversas tradiciones intelectuales un campo de debate y reflexión común en torno a la importancia de las condiciones de vida para el desarrollo de la industrialización.

Parte de dicha encrucijada se comenzó a percibir en diferentes proyectos industriales en el Chile de la década de 1920, en la medida en que presentaron la dualidad entre la costosa y lenta materialización de la racionalización maquínica, por una parte, y la asistencia y bienestar social, por otra (Venegas y Morales, 2017, 2015). Es lo que, precisamente, se observa en la cementera El Melón en la medida en que impulsó nuevas políticas para atraer fuerza de trabajo en el distrito de La Calera persuadiendo a los trabajadores para que ingresaran en la dinámica salarial moderna, pero, al mismo tiempo, seduciéndolos con mecanismos de otra naturaleza, cercanos a las prácticas de control extensivo.

De acuerdo con el control extensivo, en la nomenclatura señalada de Jean Paul de Gaudemar (1991), se propone que El Melón dispuso un modelo donde su interés por el comportamiento de la mano de obra excedía los límites del espacio productivo y se ampliaba en aquellos ocupados por el conjunto de operarios (propios o creados por las mismas sociedades industriales), incluyendo sus

\footnotetext{
${ }^{1}$ Minería practicada a pequeña escala, la mayoría de las veces en términos independientes.
} 
familias, viviendas y los tiempos dedicados al ocio y esparcimiento. Esto debía acompañarse por una suerte de higienismo médico y, principalmente, moral, lo que debía calar en la vida cotidiana de los trabajadores y en su convivencia hogareña mediante la restricción de prácticas tan nocivas como la ingesta excesiva de alcohol, las apuestas y la prostitución. El programa de intervención, entonces, debía ser capaz de incidir en el fortalecimiento de la identidad del mundo obrero, vinculando el destino de los numerosos empleados con el de la empresa y con el ámbito social cementino construido por la fábrica. La concreción de este anhelo, se propone, estuvo materialmente representada por las creaciones urbanísticas de la compañía y orientada por la necesidad de incidir en el habitar obrero, sobre todo después de la edificación de dos grandes y modernas poblaciones destinadas a albergar a empleados y obreros, ya sea en las cercanías del complejo industrial, en la ciudad de La Calera, o en las inmediaciones de la pequeña localidad de El Melón.

El concepto de habitar obrero remite a una forma de vida particular de obreros asociados a fábricas que fueron capaces de incidir en la vida cotidiana de los sujetos, mejorar considerablemente sus estándares de vivienda, salud, educación, previsión y formas de consumo pero, al mismo tiempo, desarrollaron prácticas de asociatividad fuertemente influenciados por las empresas y sus agentes específicos como las entonces llamadas visitadoras sociales (Illanes, 2001; Moyano 2016), directores de los departamentos de bienestar o jefes de población. Lo anterior se manifestó no sólo en el diseño de las viviendas y los espacios comunes, sino también en prácticas cotidianas, fiestas y formas de consumo, que llegaron a consolidar una identidad que colocó a la compañía como uno de los vértices más importantes de la vida de los sujetos, sin que se prescindiera de la vida política y sindical, o fenómenos más complejos como la huelga obrera, no obstante, su limitada frecuencia.

En complemento de la hipótesis anterior, es posible afirmar que, a diferencia de otras experiencias de paternalismo industrial, la matriz interventora de la gestión de la mano de obra implementada por El Melón, si bien presenta rasgos avanzados en la década de 1930, alcanzó su consolidación en el decenio siguiente. Entonces, se trata de una propuesta más tardía si se le compara con industrias como la azucarera de Viña del Mar o las carboníferas del sur (Venegas 2014, 2015; Morales, 2013; Vergara, 2013). Además, su política habitacional estuvo integrada en un discurso social de marcado acento católico que impregnó muchas de las actividades extensivas del Departamento de Bienestar. Así, se manifiesta un fuerte trasfondo higienista en muchas de sus iniciativas, acompañado de una propuesta moralizadora de acento cristiano, patrocinador de equilibrios y paz social tan caros a los intelectuales conservadores nacionales de raíz católica, tal como se percibe en los perspicaces trabajos del senador Juan Enrique Concha en las primeras décadas del siglo xx (Concha, 1918; Valdivieso, 2006) y que en el caso de la cementera es posible encontrar en las páginas de su periódico Cemento, editado por el Departamento de Bienestar entre los años cuarenta y setenta del siglo xx.

El artículo está organizado en tres apartados, el primero de ellos presenta algunos antecedentes de El Melón desde el punto de vista económico y su afán por el bienestar social. El segundo reconoce los componentes del programa paternalista y, por último, se reconocen las iniciativas empresariales relacionadas con su propósito de intervención urbana y en las dinámicas del habitar obrero. Finalmente se avanzan algunas conclusiones en el sentido de relacionar la gestión de la cementera con las prácticas del paternalismo industrial. 


\section{TRAYECTORIA DE UNA EMPRESA MONOPÓLICA}

La Sociedad Fábrica de Cemento de El Melón se constituyó legalmente el 12 de mayo de 1906 aunque sus estatutos fueron aprobados por decretos supremos el 13 de julio y el 15 de septiembre de ese mismo año. Se establecía como sociedad anónima, domiciliada en la ciudad de Valparaíso y su duración inicial estaba planteada por 50 años. El objetivo principal de la sociedad era:

explotar el negocio de la fabricación de cemento portland y cal y sus manufacturas, y explotar minas, fábricas y talleres que tengan por objeto extraer o elaborar materias que se empleen en la fabricación de cemento y cal y sus manufacturas o que se utilicen conjuntamente con ellos; establecer empresas de transporte para la movilización de los productos que elabore o requiera su explotación, pudiendo extenderlas a toda clase de productos, y tener participación en sociedades anónimas, colectivas o en comandita que tengan por objeto algunos de los fines expresados o cualquiera otro que interese a la sociedad (SFCM, 1918, p. 4).

La compañía entró en funciones en 1908 a partir de la utilización de piedra caliza obtenida de la hacienda El Melón, ubicada en la actual región de Valparaíso (Chermakian, 1965, p. 5). Para ello contó con un capital social inicial de 300000 libras esterlinas, representado por igual cantidad de acciones, totalmente pagadas. En adelante, se convirtió en una de las primeras fábricas productoras de cemento a lo largo de casi toda la primera mitad del siglo xx en Chile, contribuyendo a la construcción de viviendas, caminos y las principales obras públicas del país. Según precisaba Guillermo Foerster, diputado y miembro del directorio de El Melón, en 1914 el cemento de La Calera era altamente estimado por la Dirección General de Obras Públicas, que lo adquirió para desarrollar obras tan importantes como el Ferrocarril Transandino, las fortificaciones en Arica, la pavimentación de Santiago y emblemáticas construcciones como el edificio del Banco de Chile y de la Caja de Crédito Hipotecario (Boletín de la Sociedad de Fomento Fabril,1914, 1, p. 26). En este sentido su producción participó plenamente de la lenta remodelación constructiva de las principales ciudades del país.

Si bien se trató de una empresa de naturaleza monopólica, debió competir con la importación de cemento Portland, en circunstancias que su propia producción era insuficiente para cubrir la demanda nacional. En su primer año de ejercicio, produjo 11000 toneladas de cemento, es decir cerca de 260000 sacos. ${ }^{2}$ Sin embargo, en esos mismos años se importaban cerca de 70000 toneladas, las que se elevaron a algo más de 100000 en los años inmediatamente anteriores a la primera guerra mundial (Tafunell, 2007, p. 306); cifra que sólo fue superada en 1929 y 1930 , con ocasión del enorme plan de construcciones realizado por la dictadura del general Carlos Ibáñez, oportunidad en que se importaron algo más de 200000 toneladas de cemento. Ante esto, la cementera interpeló en reiteradas ocasiones al Congreso para obtener un aumento en los derechos de internación, haciéndose parte de la misma campaña que venía realizando el gremio de los industriales, nucleada desde 1883 en la Sociedad de Fomento Fabril.

A fines de 1930 la compañía se acogió a las disposiciones del arancel aduanero que autorizaba al gobierno a elevar los derechos de importación hasta $35 \%$. La medida había sido patrocinada por el gobierno de Ibáñez, que, con la idea de construir un Chile nuevo, aspiraba a una política de protección de las iniciativas nacionales de naturaleza industrial y a la necesidad de ahorrar

${ }^{2}$ Cada saco contenía 42.5 kilos de cemento. 
divisas en un momento en que los efectos de la grave recesión mundial ya se hacían sentir en el país (Henríquez, 2014, pp. 144-152). El decreto 2345 referido específicamente a la producción de cemento por la fábrica de El Melón, establecía el aumento de tasa a $35 \%$, pero además señalaba que: "Los precios posteriores fijados, podrán ser alterados por acuerdo entre el gobierno y la Sociedad Fábrica de Cemento de El Melón, si experimentaran variación las actuales condiciones de costo de producción.' ${ }^{3}$ A partir de allí, la industria tuvo que acogerse a la fijación de sus precios, pero a cambio obtuvo como garantía el reconocimiento por parte del Estado de su posición estratégica en relación con la recuperación económica del país y aún más, su participación en un espacio de negociación permanente a propósito de una variable fundamental para el mercado interno: el precio de venta del cemento. Con certeza, en 1941 se produjo la situación más compleja en estas tratativas ya que por decreto no sólo se aumentó el precio de venta, sino que el comisariato de precios dispuso la compra total de la producción y ante sí se ocupó de la comercialización de todo el cemento producido en La Calera; lo cual fue seguido en 1944 por la ley 7280, que por plazo de un año liberó de todo derecho de internación al cemento extranjero en el país.

Con todo, la relación entre los niveles de producción respecto de los indicadores de importación de cemento recorrió un camino contrapuesto (véase gráfica 1). Lo que se convirtió en una constante durante el periodo que abarca esta investigación.

Hacia 1941 El Melón experimentaba una época de expansión y estaba ad portas de incrementar sustantivamente su producción, dejando atrás sus años más difíciles desde el punto de vista económico, entre 1929 y 1934. El segundo semestre del año 1931, debido a la acumulación de 554000 sacos de cemento, paralizó parte de sus faenas hasta el mes de octubre (sFCM, 1932, pp. 2-3) y de hecho redujo su personal en forma transitoria de 677 a 611 obreros al año siguiente. En esa misma ocasión, y a pesar de que se informaron utilidades en el balance financiero por más de 5000000 de pesos en 1931, la empresa sin inconveniente redujo los salarios a sus operarios. Mediante estos y otros ajustes logró superar la crisis económica, con la misma flexibilidad que tuvo en el ciclo 1920-1922, momento en que también acusó la paralización de sus faenas ante la realización de sucesivas huelgas en sus instalaciones de La Calera.

Sin embargo, las dificultades de El Melón fueron coyunturales porque en el mediano plazo la misma crisis y la incapacidad de pagos de la economía chilena garantizaban su rápida expansión al condicionar con fuertes restricciones las importaciones de cemento (véase cuadro 1). Si en 1932 la importación sólo se situaba en 11000 toneladas, en los dos años siguientes la introducción de cemento no superó las 1000 toneladas y de hecho con la excepción de 1935, cuando se importaron 17000 toneladas, hasta 1939 el cemento extranjero fue definitivamente marginal en la economía chilena. Así, los hornos que se habían paralizado algunos meses de 1931 se encendieron en enero de 1932 y al finalizar el año se encontraba en funcionamiento un segundo horno de calcinación. Pese a esto, los administradores afirmaban que parte de sus aflicciones persistían debido a una "fuerte competencia y dificultades porque la Comisión de Control de Cambios exige entregar al Banco Central una parte del valor de la exportación en oro al cambio oficial”, es decir, todavía se dejaban sentir los efectos de la recesión internacional (SFCM, 1933, p. 3).

El incremento en la producción más decisivo de la cementera se produjo en el segundo quinquenio de los años treinta, cuando las utilidades declaradas sobre el capital se elevaron en años seguidos más de $55 \%$, alcanzando una cifra récord de $62 \%$ en 1937.4 A partir de 1934 la fábrica

${ }^{3}$ Revista Industria, 5[1938], 435-438.

${ }^{4}$ Industria, 8[1938], 547. 


\section{GRÁFICA 1. PRODUCGIÓN E IMPORTACIÓN DE GEMENTO EN CHILE, 1925-1948 (MILES DE TONELADAS ${ }^{A}$ )}

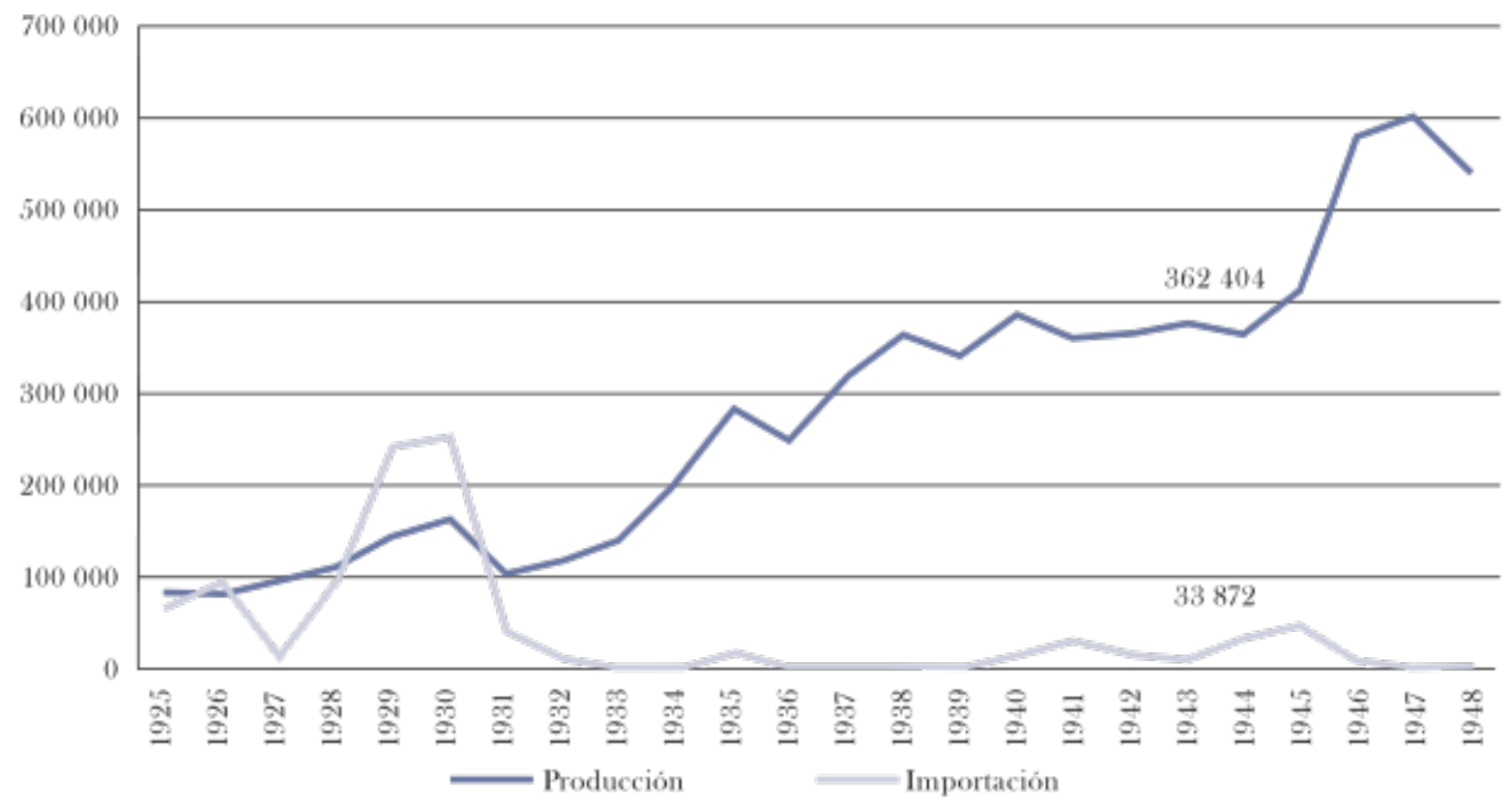

a Desde 1945, la contabilidad chilena registra lo producido en la cementera Juan Soldado, Coquimbo.

Fuente: Anuario estadístico de la República de Chile (1925-1948).

aumentó progresivamente su producción y desde el primer semestre del año siguiente funcionaba con normalidad, comenzando la ampliación de sus instalaciones. Para ello, el directorio informó a sus accionistas que se comenzaría a incorporar tecnología de Estados Unidos, esperando un aumento de la capacidad de producción hasta de $40 \%$ (sFcm, 1936, p. 3).

Con los adelantos en la producción generados gracias a la intervención de la empresa tras los años críticos inmediatos a la crisis de 1929, se observa un caso exitoso de sustitución de las importaciones. A fines de 1938 su papel monopólico no era impedimento para ser reconocida por el gremio de los industriales en la Revista Industria, editada mensualmente por la Sociedad de Fomento Fabril, que se manifestaba complacida señalando que, "con las cifras leídas queda claramente establecido que la Soc. Fábrica de Cemento El Melón está en una situación floreciente...”"5 Hacia 1945 esa condición continuaba plenamente vigente, aun cuando la Ley 7280 hizo aumentar la importación a más de 30000 toneladas en 1944 y en el rubro del cemento ya estaban en funcionamiento las faenas de otras explotaciones, que con el apoyo directo de la Corporación de Fomento de la Producción (en adelante Corfo), se establecieron en el cerro Blanco de Polpaico y en las cercanías de Coquimbo, aunque esta última fue adquirida a pocos años de entrar en explotación por la cementera de La Calera, en 1948 (Chermakian, 1965, p. 9).

Ciertamente la posición tutelar en el mercado que consiguió la Sociedad Fábrica de Cemento de El Melón se produjo por la intervención protectora del Estado al limitar la importación y promover la recuperación económica general del país, pero para el directorio había algo más: una

\footnotetext{
${ }^{5}$ Industria, 8[1938], 547.
} 


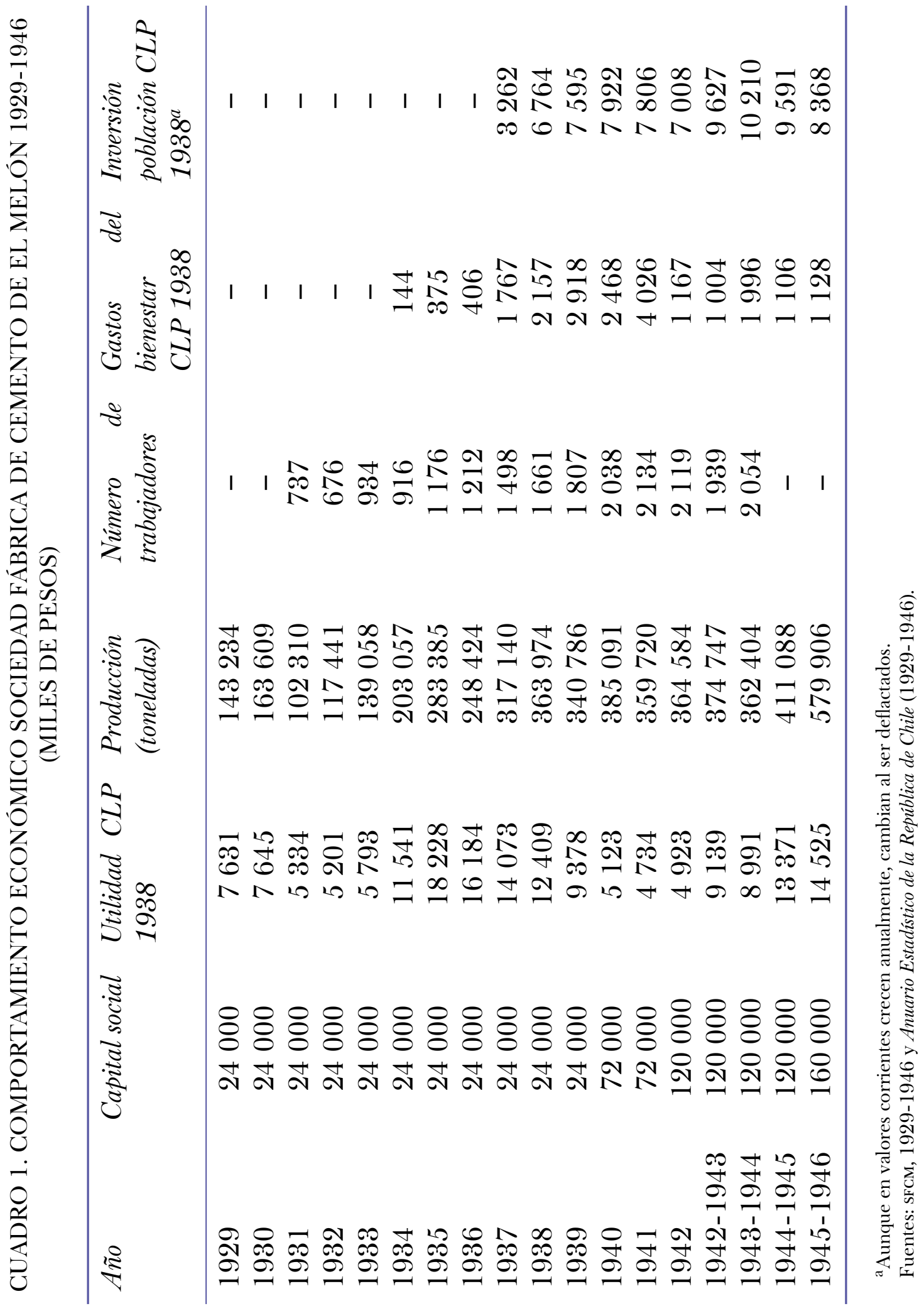


política económica austera y previsora en la época recesiva. Cuando sólo despuntaba su fase de prosperidad económica, el directorio añadía un factor de su propia incumbencia al destacar que “durante siete años no pagó a sus accionistas dividendos en efectivo y después los hizo modestos, [lo cual] ha permitido afianzar nuestra posición financiera, evitándonos pagos de intereses por el capital de explotación y permitiéndonos formar alguna reserva para las reparaciones y renovación de la maquinaria" (SFCM, 1934, p. 4). En su óptica estos recaudos le permitieron afrontar con agresividad el florecimiento económico e iniciar actividades ajenas a la producción de cemento, pero igualmente rentables. En ese plano se inscribió la consolidación de una nueva línea productiva asociada a la venta del fertilizante con Fosfatos Melón para la agricultura; además de los diversos proyectos en materia de provisión energética: primero, manteniendo su participación en la mina carbonífera de Lirquén y segundo, adquiriendo el yacimiento Cosmito, ubicado en sus proximidades, en la provincia de Concepción. Sumado a ello, la empresa también construyó la central hidroeléctrica Los Quilos con las aguas del río Aconcagua. Un proyecto que recibió la generosa inversión estatal a través de la Corfo en 1941 (Sociedad de Fomento Fabril 6, 1941, p. 399), la que facilitó 10000000 de pesos para su concreción. Así, la Sociedad Fábrica de Cemento de El Melón no sólo consiguió mayor seguridad en su abastecimiento energético al dejar de depender exclusivamente del carbón, sino que también se permitió colocar en el mercado eléctrico parte de los excedentes de su producción a la espera de sus nuevos hornos eléctricos en los años cincuenta, que estuvieron plenamente operativos en La Calera en 1959.

Ubicada en el centro de los requerimientos de la política de la industrialización dirigida por el Estado, la empresa debió plantearse nuevas metas productivas y alinearse con las políticas de la Corfo, entidad que se convirtió en el brazo ejecutor de la intervención estatal (Ortega, 1989). En esto, existieron circunstancias coyunturales que maximizaron sus oportunidades, tal es el caso del plan de reconstrucción creado tras el desastre causado por el terremoto de 1939 que afectó dramáticamente a las provincias del centro-sur del país, porque coincidió con la ampliación de las instalaciones que se venían proyectando por parte del directorio, al menos desde 1935. Entre ellas cabe destacar los nuevos hornos rotatorios adquiridos en Estados Unidos -cuya instalación experimentó demoras provocadas por el ingreso de dicho país en la segunda guerra mundial- puesto que, con ellos, la compañía esperaba conseguir un aumento de la capacidad de su producción, alcanzando hasta 500 toneladas diarias. Su idea era llegar a mediados de los años cuarenta a la producción de 1000000 de sacos mensuales, logrando la cifra récord en junio de 1946 cuando se informó a los accionistas que la producción había superado la meta autoimpuesta (sFcm, 1946, p. 3).

Para lograrlo, la compañía necesitó de inversiones en patentes comerciales, hornos, nuevas instalaciones para abastecerse de electricidad o altas gestiones políticas en las oficinas del Comisariato General de Subsidencias y Precios, entidad dependiente del Ministerio del Trabajo que reguló desde 1930 el precio del saco de cemento en el mercado local, o como ya está indicado, en las oficinas siempre generosas de la CoRfo. Estas condiciones fueron fundamentales porque le permitieron insertarse con éxito en el proceso sustitutivo de importaciones que venía gestándose en Chile, posición que se consolidó no sólo con el aumento de los precios, sino con la adquisición por parte del comisariato de la totalidad del cemento extraído de las canteras El Navío y La Calera a partir de marzo de 1941. El asunto es que, por sí mismas, todas estas iniciativas no resolvían la gestión global del negocio. Un aspecto igualmente crucial se refirió a la mano de obra que, en el periodo de los años treinta y cuarenta engrosó en forma progresiva las faenas mineras y fabriles involucradas en la elaboración del cemento, pasando de 737 operarios a principio de la década de 
1930 a algo más de 2000 en 1944, es decir, un aumento que significó casi el triple de los trabajadores comprometidos en la fábrica antes de su expansión más definitiva. Lo importante es que, en adelante, la mayor parte de dichos operarios se transformaron en una parte interesada tanto en la proyección económica de la empresa, como en sus propias condiciones laborales y de vida, tarea en que como veremos en seguida, la Sociedad Fábrica de Cemento de El Melón se ocupó con denodado esfuerzo al intentar desplegar un amplio plan de asistencia y bienestar social, aunque en el marco de una política salarial que no admitió grandes variaciones al alza. Como lo señala Robert Castel (2012) "el proletariado convertido en asalariado dotado de un estatuto de empleo tiene en adelante mucho más que perder que sus cadenas” (p. 21).

\section{LA ESTABILIDAD SOCIAL COMO REQUISITO DE LOS DESAFÍOS PRODUCTIVOS}

Muchas actividades productivas, especialmente aquellas vinculadas a la minería, vieron condicionado su emplazamiento a las cercanías de las fuentes primarias e insumos necesarios para su trabajo. Algunas experiencias industriales también debieron rendirse a esa necesidad. Este es el caso de la Sociedad Fábrica de Cemento de El Melón puesto que privilegió su localización en las cercanías de las importantes minas de piedra caliza ubicadas a escasos kilómetros de la ciudad de La Calera o del poblado de El Melón, en las inmediaciones del yacimiento El Navío. Si bien esa decisión resolvía el problema del abastecimiento oportuno y barato del principal componente del cemento Portland, dejaba abierto otro problema que la empresa debió esmerarse en enfrentar: la provisión de fuerza de trabajo, y más precisamente, la atracción y formación de obreros industriales.

La presencia de trabajadores chilenos en ocupaciones sistemáticas, modernas desde el punto de vista de la organización laboral y el uso de la tecnología, y que además aceptaran la condición salarial era bastante débil. Si bien muchos de los que se enlistaron en la fábrica habían pasado por el trabajo minero asalariado -varios de los cuales incluso habían retornado desde el norte salitrero- también era una realidad que, hasta muy avanzado el siglo xx, una parte importante de esos trabajadores había rehuido una condición salarial permanente y había preferido una vida itinerante entre la actividad pastoril, las tareas mineras por cuenta propia o un empleo temporal como complemento a una vida más autónoma (Videla, 2010). De este modo, el atractivo representado por una fábrica como la cementera El Melón debía estar en la diferencia que se establecía entre esas prácticas ancestrales y sus ofrecimientos para compensar el sacrificio de la pérdida de la libertad que los trabajadores del Norte Chico parecían defender. La estabilidad laboral y mejores salarios debían complementarse con otras prestaciones para atraer y fidelizar a la masa laboral que necesitaba para sus operaciones. Por esta misma razón es posible advertir en la gestión de la mano de obra diseñada por la Sociedad Fábrica de Cemento de El Melón un punto de inflexión, que se produce justamente en el momento en que logra acuerdos sustantivos con oficinas estatales para consolidar su posición monopólica en el mercado nacional, asegurando una fase de expansión económica.

Así, de la clásica fase de control, vigilancia y castigo que la llevó a un enfrentamiento frontal con sus trabajadores a comienzos de la década de 1920, la fábrica de La Calera transitó hacia mecanismos más sutiles y exitosos de intervención social que ayudaron a generar un clima en que muchos de los trabajadores se sintieron atraídos por la política empresarial y, aún más, mostraron evidentes signos de consentimiento hegemónico en la perspectiva que lo discutiera el sociólogo británico Michael Burawoy (1985) al examinar las distintas políticas ideológicas que han organizado la vida industrial. 


\section{CUADRO 2. JORNAL PROMEDIO NOMINAL Y DEFLACTADO DE LA SOCIEDAD FÁBRICA DE CEMENTO DE EL MELÓN, 1938-1948}

\begin{tabular}{lccccccccccc}
\hline Valor/año & 1938 & 1939 & 1940 & 1941 & 1942 & 1943 & 1944 & 1945 & 1946 & 1947 & 1948 \\
\hline $\begin{array}{l}\text { Valor peso } \\
\text { corriente }\end{array}$ & 21.84 & 25 & 29.45 & 35.81 & 42.07 & 52.9 & 61.18 & 69.35 & 75.84 & 94.11 & 116.47 \\
$\begin{array}{l}\text { Valor peso a } \\
1938^{\mathrm{a}}\end{array}$ & 21.37 & 19.17 & 20.05 & 21.17 & 19.78 & 21.40 & 22.17 & 23.09 & 21.77 & 20.22 & 21.22 \\
\hline
\end{tabular}

a Los jornales fueron deflactados a 1938 con base en Instituto Nacional de Estadísticas y en Díaz, Lüders y Wagner (2016).

Fuentes: Anuario Estadístico de la República de Chile (1938-1948), y CEPAL (1951).

Lo que se señala, según Gaudemar (1991), Sierra (1990), López (2010), Muñiz (2007), Frey (1986) entre otros, es que la cementera diseñó y puso en práctica una estrategia de control extensivo que tuvo su principal motor en el servicio de bienestar y en la política de arraigo a través de la construcción de poblaciones obreras modelos que albergaron a un importante número de sus trabajadores. Allí radicó una diferencia fundamental en la vida de las familias obreras, que, en el marco de una oferta asistencial variada provista por la empresa, convivieron con exiguos incrementos salariales (véase cuadro 2).

Los jornales de los trabajadores cementeros no sufrieron alzas que respondieran a la trayectoria económica expansiva de la empresa. Es lo que se colige cuando se correlacionan con el índice de precios al consumidor por diez años, a partir de la fecha de inauguración de la primera población obrera en 1938. De tal modo, el atractivo laboral no radicó en los ingresos autónomos que se garantizaban, más sí en el salario diferido (el conjunto de prestaciones ya señaladas) que se colocó en el horizonte próximo del obrero, su esposa, hijos e hijas.

El modelo de gestión del trabajo de la cementera se aproximó a lo que en la región venía desarrollando la Compañía de Refinería de Azúcar de Viña del Mar, pionera en la zona en materializar políticas asistenciales y de bienestar social de acuerdo con lo trabajado por Robinson Lira (1996) en un breve pero sugestivo artículo en el que aseveraba que la empresa de Julio Bernstein había logrado en los años treinta "la adhesión del sindicato" estableciendo una alianza "cuya finalidad fue contar en la industria con trabajadores 'sanos', ordenados, laboriosos y, por tanto, más subordinados” (Lira, 1996, p. 7). Un anhelo que, en las décadas de 1930 y 1940, los empresarios industriales buscaron aprovechando un marco de regulación laboral amplio y complejo, que contemplaba nuevas exigencias y posibilidades en el afán de proveer respuestas a las diferentes demandas de los sectores del trabajo (Morris, 2011).

El diseño urbano se convirtió en piedra angular de la política social de la cementera. En concordancia con experiencias industriales francesas, españolas y estadunidenses (Darley, 2010), en La Calera se edificaron dos poblaciones con clara influencia del higienismo social (Oblet, 2005), que propugnaba desde mediados del siglo xix, la creación de espacios residenciales limpios y ordenados para el cobijo de los sectores del trabajo. Gracias a esta influencia grandes capitales europeas iniciaron obras de transformación urbana e introdujeron jardines públicos, amplias avenidas y espaciosos barrios obreros. De acuerdo con David Harvey (2014) en relación con las obras de Haussmann en París, se "actuó sobre el espacio urbano como una totalidad en la que los diferentes barrios de la ciudad y las diferentes funciones se ponían en relación unas con otras para formar 
una unidad de funcionamiento" (2014, p. 143). Una unidad semejante se proyectó en el diseño urbano desarrollado por El Melón, que construyó con un afán totalizador (Sierra, 1990) dos conjuntos residenciales para sus obreros en espacios contiguos a las instalaciones productivas, donde la familia obrera cementina quedó aislada de la ciudad puesto que en su conjunto la población estuvo provista de escuelas, una iglesia, exclusivos centros deportivos y recreativos.

Pareciera que, con la puesta en práctica de este conjunto de medidas, la empresa deseaba olvidar los aciagos años de comienzos de la década de 1920 que sólo fueron conjurados por el autoritarismo ibañista (1927-1931). Entonces, un movimiento obrero politizado se había empeñado en conducir a amplias capas de mineros y a los primeros núcleos de trabajadores industriales en formación. Así, no resulta extraño que dirigentes como Luis Víctor Cruz, en su condición de diputado por el partido Obrero Socialista, visitara el pequeño pueblo de El Melón, desafiara al empresariado y animara la huelga dirigida por un consejo de la Federación Obrera de Chile que incluía trabajadores cementeros en 1921 (La Federación Obrera de Chile, 25 de diciembre de 1921). En aquella oportunidad, la huelga duró cerca de un mes (diciembre de 1921 y parte de enero de 1922) y aunque se firmaron acuerdos conciliatorios, la compañía se negó a reconocer la organización obrera, hostilizó a sus dirigentes y cometió arbitrariedades dada su capacidad de intervención en los distintos planos administrativos de la comuna: "Esta fábrica tiene injerencia interna en cada uno, y todos los actos de la vida comunal. Como si poseyera un largo brazo, ella pone la mano sobre innúmeras actividades administrativas y sociales, que están reservadas a poderes públicos privativos del pueblo. Ni los estrados de la justicia se le escapan a la gerencia de El Melón, pues todo lo invade" (La Federación Obrera de Chile 24 de febrero de 1922).

El comportamiento de la administración de la Sociedad Fábrica de Cemento de El Melón no escapó a lo obrado por otros empresarios organizados en la Asociación del Trabajo -gremio activo en enfrentar la autonomía obrera formado con anterioridad a la Confederación de la Producción y el Comercio- y aun por las autoridades políticas del Estado. Distintas fábricas, siguiendo los dictados de la asociación, mantuvieron medidas represivas contra los trabajadores como lo fueron el despido o el rechazo a la sindicalización, pero con base en la idea de conciliación y armonización del conflicto laboral, también introdujeron iniciativas tendentes a "promover el mejoramiento de la vida obrera", 6 tal como lo destacó en innumerables conferencias el director del ente gremial, Enrique Caballero, a partir de 1922 en sus recorridos por Santiago, Valparaíso y Concepción. Dicho horizonte se reprodujo en La Calera hacia los años treinta cuando la gestión de las relaciones entre los operarios y la fábrica El Melón se enmarcó en una nueva estrategia de contención de los conflictos tan propios de los periodos de tránsito económico.

\section{Diseño urbano, bienestar y compromiso social}

Tras la grave crisis de la economía chilena y mundial a comienzos de los años treinta y embarcada en un ambicioso plan de expansión a mediano plazo, la Sociedad Fábrica de Cemento de El Melón se sintió llamada a dar un golpe de timón en la gestión de su mano de obra. Una vez despejados los últimos síntomas de un ciclo recesivo en el segundo semestre de 1934, el directorio de la Sociedad Fábrica de Cemento de El Melón anunciaba la creación de su sección de bienestar social, el acto fundacional de su nueva estrategia: "La Sección de Bienestar Social recientemente organizada se

${ }^{6}$ La Patria, 18 de diciembre de 1923, p. 2. 
ha hecho cargo de todo lo relacionado con la situación de los obreros, atención médica, escuela, entretenimientos, etc., y esperamos de esta sección resultados beneficiosos para el bien general de nuestro personal" (SFGM, 1935, p. 3).

La compañía usó buena parte de su energía en un proyecto de fidelización de sus trabajadores -obreros y empleados- a través de una serie de beneficios que debían convertirse en un importante atractivo. En un primer momento el servicio de bienestar social aseguró prestaciones en asistencia social (en caso de enfermedad o retiro), medicina general y más adelante incluyó la atención dental, escuelas, instancias de ocio y diversos equipamientos que estimularon el desarrollo de prácticas deportivas y facilitaron la realización de diversos eventos culturales y celebraciones anuales, entre las que destacó la fiesta de la primavera. En 1935, los balances financieros consignan por primera vez gastos de bienestar social, con una cifra cercana a 144000 pesos, bastante menos que los 2 400000 que encierra dicho ítem en el año 1940 y, ciertamente, que los 4000000 de pesos que se imputaron en el año siguiente, justo cuando el jefe de la sección de bienestar, Carlos Morel H., fue electo regidor en la municipalidad de La Calera (véase cuadro 1).

Aunque los anuncios de la creación de una población obrera se hicieron en 1935, la obra se materializó tres años después. Se inició en el primer semestre de 1936 con la inversión de casi 2 500000 pesos, lo cual permitió edificar 100 casas para obreros y quince destinadas a la categoría de empleados, todas entregadas con anterioridad al 10 de diciembre de 1938. Pero el plan urbano era más extenso: para 1939 se contemplaba el término de otras 100 casas y se proyectaba un conjunto de 500, así como la edificación de pabellones para solteros, cuya capacidad esperada atendería las necesidades de no menos de 1700 obreros (SFCM, 1939, p. 3); tal planeación tuvo algún grado de continuidad debido a que los fondos acumulados año tras año en la construcción de viviendas se pueden estimar en cerca de 30000000 de pesos, moneda corriente, invertidos en un periodo de poco menos de una década hasta 1946 (véase cuadro 1).

Evidentemente, la política de fijar a los trabajadores en un ámbito construido por la propia industria y de acuerdo con sus reglas encerraba un interés que acompañaba su pretendida obra benefactora. Desentrañarlo requiere examinar con especificidad la forma y modalidad constructiva que asumieron las viviendas y sus equipamientos comunitarios, entendiendo que existían diferentes posibilidades y tecnologías para domiciliar a los obreros en los años treinta. En el Chile de esa época era común, por una parte, el conventillo, donde un número variable de familias compartían un largo callejón y, por otra, edificios en bloques de cuatro pisos (Hidalgo, 2005). La población Cemento inaugurada en 1938, así como otras poblaciones construidas por diferentes industrias en la misma década (Venegas y Morales, 2017), representó una vía de asentamiento diferente a ambas técnicas de diseño arquitectónico, pues el conjunto habitacional privilegiaba a través de viviendas sólidas e individuales, el recogimiento y privacidad de la familia obrera. Hasta cierto punto, las viviendas, jardines, avenidas y centros comunitarios, invitaron a que cada familia obrera se autorregulara como unidad doméstica. De este modo, El Melón no sólo domicilió a sus operarios, sino que también se propuso transmitir normas de convivencia social, de salud pública, higiene familiar y comportamiento, en todo lo cual la empresa se apoyó en sus cuadros administrativos y en la permanente presencia de representantes de la Iglesia católica, miembros que alcanzaron un lugar privilegiado en la población al participar de manera habitual en su sociabilidad al involucrarse, por ejemplo, en el mantenimiento de la escuela de varones, dirigida por la Congregación de los Hermanos Maristas. 
Atraídos por el experimento urbano de los empresarios de El Melón, los editorialistas de la Revista Industria dieron a conocer la novel población Cemento, inspirada en "un plan de satisfacción social para los asalariados, que a la vez que permita exigirles un máximum de actividad, esos trabajadores puedan cumplir sus funciones dentro de un mínimum de comodidades y bienestar que les haga más llevadera y grata su labor:'7

La población era única en su género y un verdadero ejemplo de vida higiénica: "demos una ojeada a la población misma. Un centenar de casas de un piso, pintadas con un color amarillo muy agradable, forma las calles por las cuales discurrirá más adelante una vida activa y feliz. Las calzadas tienen pavimento de concreto, las aceras, con árboles ya plantados, cuentan también con pavimento del mismo material y con espacios para jardines frente a cada habitación.' 8

La descripción destacaba el carácter de conjunto y las consideraciones estéticas que conservaba la población en su inauguración, siguiendo las proposiciones que en el clima intelectual anglosajón se dieron a conocer bajo la escuela de la ciudad jardín. Según Margaret Crawford en la planificación de las comunidades industriales progresivamente se fueron adoptando modelos de responsabilidad social y grandes empresas de Estados Unidos se comprometieron a elevar las condiciones de vida de los trabajadores a fines del siglo XIx (1999, pp. 51-52). Para ello una de las medidas más llamativas se tradujo en modernas viviendas para los obreros insertas en jardines, áreas verdes y amplias avenidas (Miller, 2002, p. 99), que acentuaron el contraste paisajístico resultante de la contraposición entre la monotonía de la fábrica y una adecuada vida hogareña. Así, resulta coherente que las viviendas de la población Cemento contemplaran antejardines y huertos con árboles frutales, a la usanza arquitectónica y urbanística empleada en diversas experiencias europeas (Miller, 2002, pp. 99-101). Es lo que se colige de los planos de las primeras viviendas obreras de dicha población.

En la población "todas estas casitas cuentan con servicios higiénicos completos y reciben aire, luz y sol en perfectas condiciones" 9 bondades que se acentuaban por una manifiesta preocupación paisajística en el sentido de que "los cerros enmarcan la población, y en medio se destacan las notas amarillas de las casas como un alegre penacho de plumas de ave".10 A esto se agregaban los espacios interiores y la distribución de las edificaciones. Cada vivienda para empleados era de 110 $\mathrm{m}^{2}$ e incluía "Living room, tres dormitorios, un comedor, sala, toilette, cocina, despensa, pieza servidumbre, WC servidumbre" 11 Esto indica que los espacios interiores habían sido minuciosamente diseñados y se alejaban ostensiblemente de las formas tradicionales de habitación obrera o popular en la medida en que estaban acondicionadas para familias nucleares que no admitían parentescos extendidos ni allegados circunstanciales. Del mismo modo, cada unidad establecía una clara distinción de los espacios y una especialización de los mismos. Los dormitorios, sala de estar y la cocina aislada del resto de los habitáculos, alentaban la especialización del trabajo femenino y la reclusión de la mujer en el hogar. En el caso de las casas destinadas a los obreros, se reproduce un patrón semejante aunque en un espacio doméstico más reducido ya que la edificación alcanzaba $75 \mathrm{~m}^{2}$ construidos, donde se distribuía un living room, hasta tres dormitorios, una cocina y baño en el interior del domicilio.

\footnotetext{
${ }^{7}$ La población obrera de la Sociedad Fábrica de Cemento El Melón (1939). Revista Industria, 2, 91.

${ }^{8}$ El Mercurio de Santiago, 14 de diciembre de 1938, p. 20.

${ }^{9}$ Revista Industria, 2[1939], 91.

${ }^{10}$ El Mercurio de Santiago, 14 de diciembre de 1938, p. 20.

${ }^{11}$ Revista Industria, 2[1939], 91.
} 
FIGURA 1. VIVIENDAS OBRERAS POBLACIÓN CEMENTO (1938)

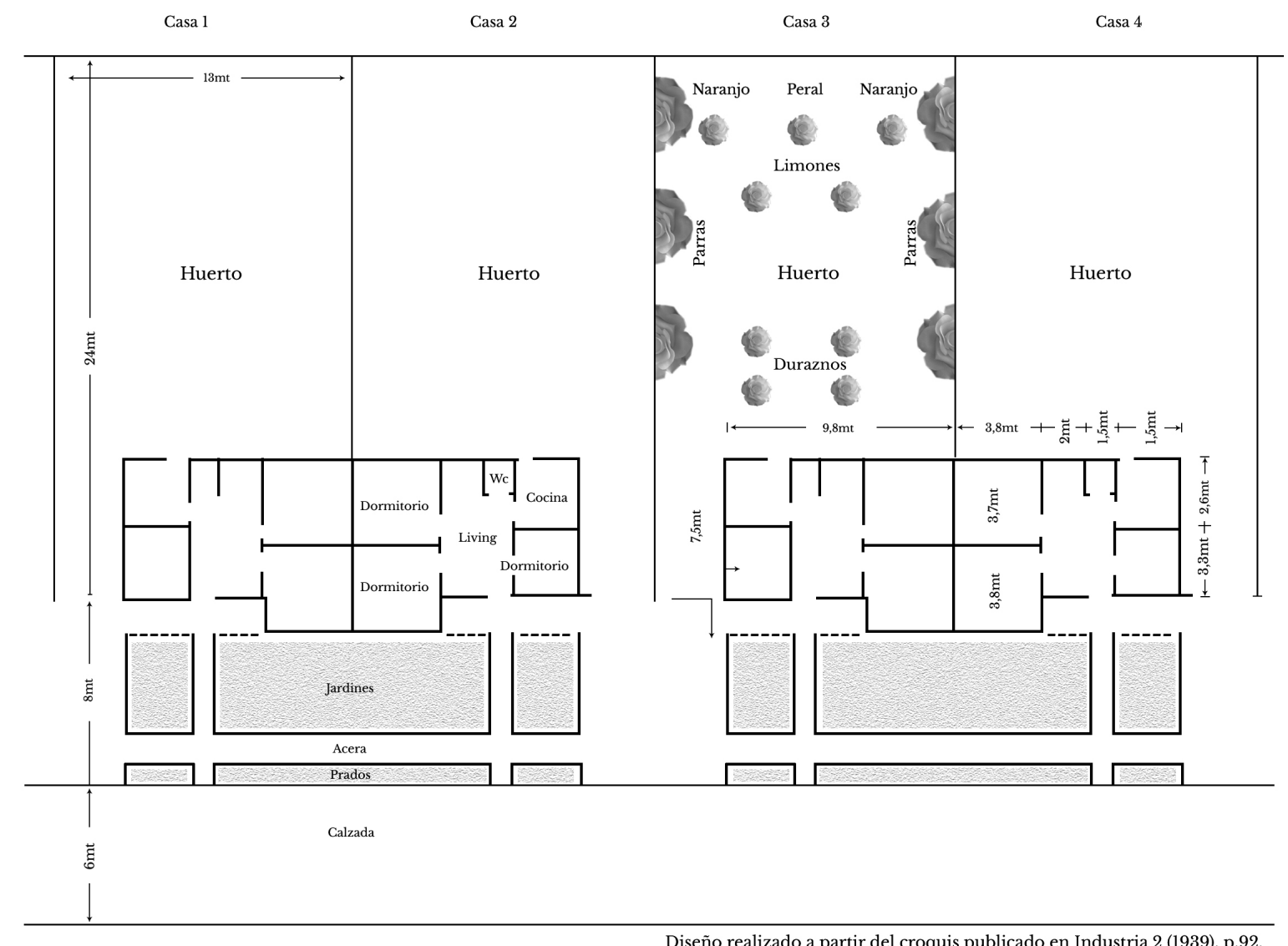

Fuente: Revista Industria, 2[1939], 92.

En sí mismo, un patio suficiente para el desarrollo de huertos provisto de parras y árboles frutales (véase figura 1), el baño interior y la cocina separada de todas las habitaciones de cada casa, eran tecnologías que pocas familias obreras habían alcanzado a fines de los años treinta. Sobre estos nuevos materiales constructivos, amplios espacios para la vida familiar y un paisaje urbano articulado sobre avenidas limpias y jardines, los obreros comenzaron a forjar un nuevo habitar en El Melón. En él, el higienismo, sea en su vertiente física o moral, se vuelve una matriz útil para interpretar lo que fue destacado en la época por su singularidad y excepcionalidad: el orden, la amplitud y armonía del conjunto barrial, la limpieza, áreas verdes y la luminosidad del proyecto.

Por cuanto se reparó en los beneficios del proyecto habitacional: "Si se atraviesa la calle que separa los dos recintos, se ve un cambio fundamental. En La Calera no hay pavimentos sólidos, ni duraderos, ni hay este lujo de árboles y esta animación de coloridos que se ven en la población 'El Melón'. Mientras todo en aquella es gris, terroso, polvoriento, porque años de incuria y de pobreza se han detenido allí, en 'El Melón’ todo ríe y todo canta” 12

${ }^{12}$ El Mercurio de Santiago, 14 de diciembre de 1938, p. 20. 
La incuria no sólo era fruto del contraste de los domicilios obreros predominantes en La Calera y El Melón. Esto era algo palpable a la vista de cualquier observador, pero no era lo único en la medida que el servicio de bienestar de la Sociedad Fábrica de Cemento de El Melón junto con realizar inversiones consecutivas en la ampliación de sus poblaciones, procuró asistencia social y un cúmulo de diferentes iniciativas que buscaron intervenir directamente en el bienestar de la familia obrera. Así se tiene que el complejo urbanístico consideró entre otros un policlínico, una cooperativa de consumo, baños y lavandería, sala de teatro, plazas de juegos infantiles, piscina y restaurant popular. Todo ello daba cuenta de un esfuerzo global diseñado a transformar las pautas de comportamiento obrero, sea en sus nociones sobre el consumo o gasto de los salarios, como en sus nociones sobre la higiene o la limpieza. Esto igualmente se percibe en la provisión de huertos en cada residencia obrera, pues con ellos se intentaba que los miembros de la familia obrera utilizaran sus tiempos libres en forma productiva, sana y privada. El huerto en cada vivienda, el variado equipamiento comunitario y de entretenimiento que acompañaron a la población, dieron vida y forjaron las relaciones de los trabajadores fuera de las maestranzas, talleres, hornos y los yacimientos mineros. Considerando todo ello el contraste con la ciudad de La Calera era aún más radical, puesto que los servicios médicos y educacionales, así como el gimnasio o el estadio, eran incomparablemente mejores que cualquier otro al que tuvieran acceso los trabajadores de la ciudad.

El complejo urbanístico, contó desde sus inicios con una escuela de varones. Esta se edificó sobre una superficie de $10800 \mathrm{~m}^{2}$, tuvo un costo de 883000 pesos y una capacidad inicial de 450 estudiantes. La iniciativa fue encargada a la Congregación de los Hermanos Maristas, con un grupo de seis profesores religiosos y catorce civiles, considerando una nómina anual de 120000 pesos en su primer año de funcionamiento, en 1937, orientada tempranamente a la formación de cuadros técnicos destinados a servir en la propia fábrica. Aunque hasta abril de 1941 se tuvo que esperar la apertura de una escuela semejante para mujeres, la presencia de dicha congregación tiñó no sólo las actividades escolares con su enseñanza confesional, sino las más variadas instancias de sociabilidad que se desplegaron en el interior del recinto residencial. En cada ceremonia, fiesta o agasajo entregado a obreros premiados por alguna circunstancia especial, algún miembro de la congregación tomó un lugar especial, el mismo que ocupó el obispo de Valparaíso en la inauguración de las viviendas en 1938. Este rasgo, tan acusado en El Melón, no es fácil hallar en otras experiencias donde las industrias montaron servicios completos de bienestar (Videla, Venegas y Godoy, 2016), o al menos no con la intensidad y cobertura que obtuvieron en la compañía gestionada por Enrique Ariztía pues junto con tomar un lugar privilegiado en la escuela de hombres, que llegó a tener una matrícula de 1200 estudiantes en 1941, también lo alcanzaron en la Revista Cemento que comenzó a circular ese año, lugar desde donde se difundieron habitualmente "colaboraciones al servicio de la moral" firmados por el capellán de la escuela u otro miembro de la misma.

Hasta qué punto fue relevante la escuela financiada por la empresa para crear un tipo de relaciones laborales armoniosas, no es algo que se pueda esclarecer, pero su incidencia tuvo que ser importante si se complementa con las otras garantías a las que accedieron con regularidad los trabajadores y sus respectivas familias. En ese ámbito destaca el complejo deportivo que se diseñó sobre tres hectáreas colindantes a la población por un costo inicial de 382400 pesos. Consideraba "tribunas de concreto con 1200 asientos y 8 camarines con servicios higiénicos y un Buffet, 2 
canchas de Tennis, una cancha de Basket-ball, 1 cancha de Foot-ball, velódromo, foso de saltos":13 infraestructura que dejaba de manifiesto el interés por, si no administrar el tiempo libre de los trabajadores, al menos orientarlo hacia una vida sana y virtuosa a través del deporte. Una perspectiva similar llevó a la compañía a patrocinar también la consolidación de un club deportivo que animó las competencias de fútbol a nivel nacional, que además recibió la visita de clubes del fútbol profesional como Colo Colo o la Universidad Católica en la década de los cuarenta, lo que seguramente incidió en la sensación de menor aislamiento de quienes vivían en la burbuja urbanística creada por el servicio de bienestar.

A esta notable infraestructura urbana se fue agregando una serie de otras construcciones que se integraron al complejo programa de gestión, que, en su aspecto medular, estuvo organizado desde la oficina de bienestar y, en particular, por la activa labor realizada por las asistentes sociales. Hacia los años veinte, dichas profesionales se involucraron en los recintos industriales, primero como facilitadoras de la implementación de las normativas de legislación social -accidentes laborales, cargas familiares u otras- y, junto con ello, para contener y resolver de problemáticas domésticas en los núcleos familiares de cada operario. Como lo ha sostenido Karin Rosemblatt (1995), la promoción de dichos núcleos se transformó en un aspecto crucial de las políticas asistenciales del Frente Popular. Al respecto, por ejemplo, Raquel Fernández, asistente de Cristalerías de Chile, señalaba que era prioritario educar al obrero pues se "le enseña la manera de aprovechar lo que le ofrece la comunidad, le inculca aspiraciones, le enseña el ahorro, higiene, da nociones de puericultura a la esposa, la orienta en la confección de menú sano, propicia el buen empleo de las horas libres de él y de su familia", 14

En El Melón, el papel de las asistentes sociales era central y por lo mismo se proyectaron dos casas de $110 \mathrm{~m}^{2}$ para que dichas funcionarias convivieran cotidianamente con la población obrera. Las primeras asistentes habían sido contratadas en 1933 y con su experiencia se hicieron cargo de poner en práctica el servicio de bienestar (Alexander, 1949, p. 374). Ellas mantuvieron un entendimiento directo con las familias obreras, realizaron permanentes visitas a sus domicilios y se entrevistaron preferentemente con las esposas y dueñas de casa, con lo que se naturalizó su labor social en la medida en que se convirtieron en el brazo ejecutor del proyecto interventor y modelador de la empresa.

Todo lo anterior muestra un panorama muy distinto al que habitaba la gran mayoría de los trabajadores chilenos de extracción popular, no solamente del mundo urbano, sino también de los espacios rurales cercanos al que se emplazaba la cementera. La influencia del espacio físico, los materiales de construcción, el diseño y distribución de las viviendas actuaron sobre las personas, y si bien estas construyeron sus propias dinámicas, no lograron zafarse completamente de las orientaciones impuestas verticalmente. La mayor parte de los hijos e hijas de los trabajadores fueron a las escuelas administradas por la compañía y la Iglesia católica acompañó la vida cotidiana de sus poblaciones obreras. Del mismo modo, la visita de las asistentes sociales se constituyó en un evento periódico de los hogares cementeros. Todo ello se hizo ostensible en la percepción de algunos de los ex trabajadores, manifestado en una expresión de genuina gratitud habitual: "todo se lo debo a la empresa”. Aún hoy, quienes recibieron los beneficios de la compañía se manifiestan en ese mismo tenor, la mayoría de los recuerdos tienden a reforzar los lazos identitarios en una dimensión positiva.

${ }^{13}$ Revista Industria, 2[1939], 92.

${ }^{14}$ Servicio Social, 4[1939], p. 272. 


\section{Conclusiones}

La Sociedad Fábrica de Cemento de El Melón fue distinguida en los círculos empresariales como una de las principales compañías que emprendió una decidida campaña por mejorar sustantivamente las condiciones de vida de sus obreros y empleados. De acuerdo con la Sociedad de Fomento Fabril dicha actitud se rodeaba de un aura benefactora. Suponiendo que haya sido de ese modo, claramente las estrategias utilizadas por estas empresas y particularmente por la compañía cementera, constituyeron un plan diseñado para gestionar la fuerza de trabajo y evitar los conflictos frontales que en los años previos al autoritarismo ibañista (1927-1931) habían distanciado al capital y al trabajo.

La búsqueda de la paz social estuvo en el centro de la gestión social empresarial, lo que cobraba particular importancia en momentos en que la industria El Melón disponía de prácticamente todos los factores a su favor para consolidar su posición de privilegio en la escena económica nacional de Chile.

Como única iniciativa en condiciones de cubrir la demanda local de cemento, la compañía gozó de ventajas incomparables respecto de otras experiencias de la nación chilena. Amparada, a lo menos hasta 1944, por una legislación aduanera favorable, pudo capitalizar esas ventajas ampliando su capacidad productiva, a la vez que copaba la oferta chilena de cemento. Sin duda los años que van desde 1934 hasta 1946 constituyen, en la primera época de formación de la industria, su periodo de mayor dinamismo y transformación. El desempeño de la compañía fue exitoso y por lo mismo estuvo en condiciones de ensayar una forma particular de control sobre uno de los factores productivos más complejos, la mano de obra. Para ello, si bien buscó incidir en términos políticos a nivel de la institucionalidad local (en la municipalidad, por ejemplo) y de la organización política de los trabajadores (particularmente a nivel sindical), concentró sus afanes más bien en la intervención y diseño de los espacios sociales que involucraban al conjunto de trabajadores y las relaciones resultantes. Vínculos que iban desde el comportamiento al interior de la fábrica, hasta aquellos que normaban la vida cotidiana, pública y privada, de la familia cementina. La acción empresarial tuvo en el hogar obrero su principal foco de atención y herramienta de intervención social y por ello dedicó sus mayores esfuerzos y recursos a definir una política urbana coincidente con esa importancia. La construcción de este mundo ideal debía ser la llave que asegurara la continuidad de los trabajos y, más importante aún, la fidelización de sus trabajadores. La casa, la población y la fábrica, puesto que tuvieron continuidad funcional y proximidad, constituyeron una fuerte seña de identidad obrera que difícilmente encontraron en otro elemento de identificación. Se trataba de la formación de una clase obrera diferenciada que paulatinamente dejaba atrás los estragos de la pobreza y se encaminaba, de la mano empresarial, a una sociedad de consumo. Una sociedad con rasgos y formas de vida urbana y moderna marcada por la difusión de nuevas pautas de consumo doméstico.

Esa identidad fue disputada desde el sindicato, el partido político y las legítimas acciones de resistencia de los trabajadores como es posible constatar en torno a 1941, momento en que la compañía enfrentó una oleada de agitación obrera patrocinada por el Partido Comunista, que se mantuvo en el manejo de los conflictos con la empresa hasta 1946 (Peñafiel, 2017). Sin embargo, la penetración empresarial por la vía del paternalismo fue un difícil escollo para lograr la autonomía plena del obrero industrial involucrado en ese tipo de experiencias. La construcción de un modo de ser paternalista no fue privativa de la experiencia de El Melón, aunque encontremos en él uno de los ejemplos más acabados. Con seguridad se puede afirmar que lo que vivió El Melón 
tuvo como complemento un listado de otros complejos industriales que mantuvieron a lo largo de nuestro país componentes del paternalismo industrial hasta mediados del siglo xx y, según el caso, algunos años más. La Compañía de Cervecerías Unidas, Cristalerías de Chile, Manufactura de Papeles y Cartones de Puente Alto, Fábrica Nacional de Sacos, Fábrica Nacional de Paños Tomé, Fábrica Nacional de Loza de Penco, Refinería de Azúcar de Viña del Mar, Yarur Manufacturas Chilenas de Algodón, Manufacturas SUMAR o Manufacturas de Cobre (MADECo), compartieron un modo de gestión de la fuerza de trabajo que excedió los ámbitos propiamente productivos y canalizó sus esfuerzos para crear la ficción de la familia industrial, aun cuando en la cementera existieron rasgos singulares como la activa presencia de la Iglesia católica en la cotidianidad de sus recintos residenciales, asumiendo un papel protagónico en la educación y en cada liturgia cívica organizada por los servicios de bienestar. El mismo que asumió en la Revista Cemento, donde el mensaje religioso se transformó en un insumo regular de la lectura de la comunidad obrera de la fábrica. Este rasgo no es fácil de observar en las empresas carboníferas y textiles del centro-sur del país ni en los programas de asistencia creados en grandes empresas de Santiago, como Sumar o Madeco.

De esta forma, es muy probable que los trabajadores, motivo de esta gestión, hayan mejorado realmente sus condiciones de existencia en términos concretos aun cuando, según se observó, no alcanzaran aumentos sustantivos en sus jornales durante diez años a partir de 1938. Y, además, es posible que retrocedieran en términos de su autonomía e identidad proletaria pues las garantías sociales a las que accedieron debieron ser sopesadas en cada momento crítico de su lucha por incrementar demandas sociales. En algunos casos sacudieron la impronta paternalista y avanzaron en su identificación de clase, en otros sucumbieron a sus ventajas y se pusieron al lado de la patronal defendiendo posturas que creyeron comunes.

\section{Lista de ReFERENCIAS}

Alexander, R. (1949). Industrial social workers in Chile. Social Service Review, 23(3), 373-376.

Boltanski, L. y Chiapello, E. (2002). El nuevo espíritu del capitalismo. Barcelona: Akal.

Burawoy, M. (1985). The politics of production: factory regimes under capitalism and socialism. London: Verso.

CaStel, R. (2012). El ascenso de las incertidumbres: trabajo, protecciones, estatuto del individuo. Buenos Aires: Fondo de Cultura Económica.

Chermakian, J. (1965). Desarrollo y características actuales de la industria del cemento en Chile. Revista Geográfica, 35(63), 5-32.

Chile. Oficina Central de Estadística (1920). Anuario Estadístico de la República de Chile. Santiago: Imprenta Nacional.

Comisión Económica para América Latina y el Caribe (1951). Estudio económico de América Latina 1949, Anexo I. Nueva York: Naciones Unidas.

Concha, J. E. (1918). Conferencias sobre economía social dictadas en la Universidad Católica de Santiago de Chile. Santiago: Imprenta Chile.

Coriat, B. (2011). El taller y el cronómetro: ensayo sobre el taylorismo, el fordismo y la producción en masa. México: Siglo XXI.

Crawford, M. (1999). The "new" company town. Perspecta, 30, 48-57.

DARLEY, G. (2010). La Fábrica como arquitectura: facetas de la construcción industrial. Barcelona: Reverté. 
DíAz, J., LüDERs, R. y WAGner, G. (eds.). (2016). Chile 1810-2010: la república en cifras: historical statistics. Santiago: Universidad Católica.

Díez, F. (2014). Homo faber: historia intelectual del trabajo, 1675-1945. Madrid: Siglo XXI España.

FERNÁNDEZ, E. (2015). Estudio sobre la génesis y la realización de una estructura urbana: la construcción de la red de alcantarillado de Santiago de Chile (1887-1910). Historia, 48(1), 119193. Dor: 10.4067/S0717-71942015000100005

Fujalkov, Y. (2012). L'hygiénisme au chevet de la ville malade. En A. LÉvy (ed.), Ville, urbanisme E̊ santé: les trois révolutions (pp. 113-136). París: Éditions Pascal Paris.

FRey, J. P. (1986). La ville industrielle et ses urbanités: la distinction ouvriers/employés, Le Creusot 18701930. Liège: Pierre Mardaga.

Gaudemar, J. P. de (1991). Preliminares para una genealogía de las formas de disciplina en el proceso capitalista del trabajo. En M. Foucault, J. Donzelot, C. Grignon, J. P. de Gaudemar, F. Muel y R. Castel (eds.), Espacios de poder (pp. 85-121). Madrid: La Piqueta.

Harvey, D. (2008). París, capital de la modernidad. Madrid: Akal.

HenRíquez, R. (2014). En «estado sólido»: políticas y politización en la construcción estatal: Chile, 19201950. Santiago: Pontificia Universidad Católica de Chile.

Hidalgo, R. (2005). La vivienda social en Chile y la construcción del espacio urbano en el Santiago del siglo $X X$. Santiago: Instituto de Geografía PUC/Centro de Investigaciones Diego Barrios Arana.

ILlanEs, A. (2001). Ella en Lota-Coronel: poder y domesticación: el primer servicio social industrial de América Latina. Mapocho, 49, 141-148.

KIRSCH, H. W. (1977). Industrial development in a traditional society: the conflict of entrepreneurship and modernization in Chile. Gainesville: University Presses of Florida.

Lemiez, G. (2007). Relaciones laborales paternalistas en la industria del cemento. El caso de Calera de Avellaneda. Olavarría, 1935-1975. Recuperado de http://www.eumed.net/libros-gratis/2013a/1238/ index.htm

LIRA, R. (1996). Modelo de relaciones industriales y orientación sindical. El caso de la Refinería de Azúcar de Viña del Mar, 1930-1973. Proposiciones, 27, 1-28.

LóPEz, P. (2010). Del campo a la fábrica: vida y trabajo en una colonia industrial. Madrid: Los Libros de la Catarata.

Melling, J. (1992). Welfare capitalism and the origins of welfare states: British industry, workplace welfare and social reform, c. 1870-1914. Social History, 17(3), 453-478. Dor: 10.1080/ 03071029208567850

Miller, M. (2002). The origins of the garden city residential neighborhood. En K. C. PARsons y D. Schuyler (eds.), From garden city to green city: the legacy of Ebenezer Howard (pp. 99-131). Baltimore: Johns Hopkins University Press.

Mondragón, H. (2010). El discurso de la arquitectura moderna. Chile 1930-1950. Una construcción desde las publicaciones periódicas (Tesis de doctorado). Pontificia Universidad Católica de Chile, Chile.

Morales, D. (2013). El paternalismo industrial en la Fábrica de Paños Bella-Vista Tomé, 1910-1935 (Tesis magíster). Universidad de Santiago de Chile, Santiago.

Morris, J. O. (2011). Las elites, los intelectuales y el consenso: estudio de la cuestión social y del sistema de relaciones industriales de Chile. Santiago: Editorial del Pacífico.

Moyano, C. (2016). La visitadora social industrial en Chile: tradición y modernidad en la gestión del bienestar, 1920-1950. Nuevo Mundo Mundos Nuevos. Dor: 10.4000/nuevomundo.69328 
Muñız, J. (2007). Del pozo a la fábrica. Genealogías del paternalismo minero contemporáneo en Asturias. Oviedo: Universidad de Oviedo/Trea.

MuÑoz, O. (1968). Crecimiento industrial en Chile: 1914-1965. Santiago: Instituto de Economía y Planificación.

Овцет, T. (2005). Gouverner la ville: les voies urbaines de la démocratie moderne. París: Presses universitaires de France.

Ortega, L. (1989). CORFO, Cincuenta años de realizaciones 1939-1989. Santiago: Universidad de Santiago de Chile.

Ortega, L. (2012). La crisis de 1914-1924 y el sector fabril en Chile. Historia, 45(2), 433-454.

Palma, G. (1984). Chile, 1914-1935. De economía exportadora a sustitutiva de importaciones. CIEPLAN Colección Estudios, 12, 61-88.

PEÑAfiel, O. (2017). Paternalismo Industrial, conflicto obrero y producción hegemónica en cemento melón, La Calera, 1938-1958 (Tesis magíster). Universidad de Santiago de Chile, Chile.

Rosemblatt, K. (1995). Por un hogar bien constituido. El Estado y su política familiar en los Frentes Populares. En L. Godoy (ed.), Disciplina y desacato. Construcción de identidad en Chile, siglos XIX y XX. Santiago: Sur/Centro de Estudios para el Desarrollo de la Mujer.

ShapaYer-Makov, H. (2004). Control at the workplace: paternalism reinvented in Victorian Britain. En C. Emsley, E. Johnson y P. Spierenburg (eds.), Social control in Europe. Vol. 2: 18002000. Columbus: Ohio State University.

SIERRA, J. (1990). El obrero soñado: ensayo sobre el paternalismo industrial: Asturias, 1860-1917. Madrid: Siglo XXI Editores.

Sociedad Fábrica de Cemento de El Melón. (1920). Balance y memorias. Santiago: Autor.

TAfunELl, X. (2007). On the Origins of ISI: The Latin American Cement Industry, 1900-1930. Journal of Latin American Studies, 39(2), 299. DOI: 10.1017/S0022216X07002398

Valdivieso, P. (2006). Dignidad humana y justicia: la historia de Chile, la política social y el cristianismo 1880-1920. Santiago: Ediciones Universidad Católica de Chile.

VEnegas, H. (2014). Paternalismo industrial y control social. Las experiencias disciplinadoras en la minería del carbón en Chile, Lota y Coronel en la primera mitad del siglo XX. Amérique Latine Histoire et Mémoire. Les Cahiers ALHIM, 28. Recuperado de http://journals.openedition.org/ alhim/5099

Venegas, H. (2015). Políticas de bienestar y control social en la minería del carbón. Las experiencias de Lota y Coronel en el siglo XX. Atenea, 511, 221-245. Dor: 10.4067/S071804622015000100012

Venegas, H. y Morales, D. (2015). El despliegue del paternalismo industrial en la Compañía Minera e Industrial de Chile (1920-1940). Historia Crítica, 58(40), 117-136. Dor: 10.7440/ histcrit58.2015.06

Venegas, H. y Morales, D. (2017). Un caso de paternalismo industrial en Tomé: Familia, espacio urbano y sociabilidad de los obreros textiles (1920-1940). Historia (Santiago), 50(1), 273-302. DOI: 10.4067/S0717-71942017000100010

Vergara, A. (2013). Paternalismo industrial, empresa extranjera y campamentos mineros en América Latina: un esfuerzo de historia laboral y transnacional. Avances del Cesor, 10(10), 113-127.

Videla, E. (2009). Movimiento pendular de una economía dual. Departamento de Ovalle. Valle del Limarí. 1870-1930. En L. Ortega, M. Godoy y H. Venegas (eds.), Sociedad y minería en el Norte Chico, 1840-1930. Santiago, Chile: Universidad Academia de Humanismo Cristiano. 
Videla, E., Venegas, H. y Godoy, M. (eds.). (2016). El orden fabril: paternalismo industrial en la minería chilena 1900-1950. Valparaíso: America en Movimiento Editorial.

\section{Hemerografía}

Boletín de la Sociedad de Fomento Fabril, 1908-1930, vols. 25-47. Santiago, Chile: Sociedad de Fomento Fabril

El Mercurio de Santiago, 1920-1923, 1937-1939. Santiago, Chile.

La Federación Obrera de Chile, 1918-1924. Santiago, Chile.

La Patria. Santiago, Chile.

Servicio Social. Santiago, Chile.

Revista Industria, 1935-1950. Sociedad de Fomento Fabril,Santiago, Chile.

Revista Cemento. Santiago, Chile. 